\title{
Study on Spatio-Temporal Change of Ecological Land in Yellow River Delta Based on RS\&GIS
}

\author{
GuoQiang $\mathrm{An}^{1,2, *}$ \\ ${ }^{1}$ Shandong Land Surveying and Planning Institute, 250014 Jinan, Shandong, China \\ ${ }^{2}$ Shandong Scientific Research Base for Key Laboratory of Land Use Ministry of Land and Resources, Jinan, Shandong 250014, China
}

\begin{abstract}
The temporal and spatial variation of ecological land use and its current distribution were studied to provide reference for the protection of original ecological land and ecological environment in the Yellow River Delta. Using RS colour synthesis, supervised classification, unsupervised classification, vegetation index and other methods to monitor the impact of human activities on the original ecological land in the past 30 years; using GIS technology to analyse the statistical data and construct the model of original ecological land area index to study the ecological land distribution status. The results show that the boundary of original ecological land in the Yellow River Delta had been pushed toward the coastline at an average speed of $0.8 \mathrm{~km}$ per year due to human activities. In the past 20 years, a large amount of original ecological land gradually transformed into artificial ecological land. In view of the evolution and status of ecological land in the Yellow River Delta, related local departments should adopt differentiated and focused protection measures to protect the ecological land of the Yellow River Delta.
\end{abstract}

\section{Introduction}

The construction of ecological civilization is an important part of socialism with Chinese characteristics in the new era. Studying the evolution and layout of ecological land is not only an important scientific issue, but also a social issue that concerns the ecological and environmental protection of China. Ecological land with water protection, soil conservation, biodiversity conservation and many other ecological functions, is the quality of regional ecological and environmental "barometer" [1]. Many Chinese scholars deeply studied the concept of ecological land use [2], classification $[2,3,4]$ and the distribution pattern of ecological land in China $[1,4]$, and laid the foundation for further studies as evolution of regional ecological land use [5], the driving forces [6] and etc. However, the related literature on the ecological land in the Yellow River Delta is still rare. This paper makes use of the data of remote sensing and land survey to study the evolution trend and distribution of ecological land in the Yellow River Delta in recent 30 years, which is of great significance for the protection of the ecological environment in the Yellow River Delta and the sustainable development of the region. The typical demonstration of related research on regional ecological evolution and layout of land use offered as well.

\section{Study areas}

The Yellow River Delta is located in the North-east of Shandong Province, on the south bank of the Bohai Gulf and the west coast of Laizhou Bay. It is one of the three major delta estuaries in China, and is the most concentrated area for ecological use in Shandong Province. The total land area is $16165.56 \mathrm{Km} 2$, including all of Dongying City and the most of Binzhou City, with a total population of 5.21 million. There are mainly three rivers, including the Yellow River, Xiaoqing River, Tuhai River, Magu River here. In recent years, human activities have a very strong impact on the Yellow River Delta region, and the area and catigories of ecological land have undergone fundamental changes. Among them, wetland, saline-alkali land and waters which have the leading function of ecology and environment have rapidly reduced, while artificial ecological land, nonecological land continue to increase. To a certain extent, the tendency of ecological land change in the Yellow River Delta reflects the trend of the national ecological land use, especially in the east coast where the economy and society have developed rapidly in recent years.

\section{Data and processing}

\subsection{Remote sense data}

Landsat 4-5 TM data of six periods of 1985, 1990, 1995, 2000, 2005, 2010, and Landsat 8 OLI_TIRS data of 2015 were used to analyse the impact of human activities on the boundary of original ecological land in the Yellow River Delta for nearly 30 years. Sequence data of six periods were formed for the dynamic monitoring. The data set is provided by Geospatial Data Cloud site,

\footnotetext{
* Corresponding author: an_tiger_@163.com
} 
Computer Network Information Centre, Chinese Academy of Sciences. (Http://www.gscloud.cn). In order to establish a uniform standard for interpretation, Landsat4-5 TM data was simulated by real colour synthesis using the red (band3), the green (band2) and the blue (band1).For the Landsat 8 OLI_TIRS data, the true colour synthesis is performed in $\operatorname{Re} \bar{d}(\operatorname{Band} 4)$, Green (Band3) and Blue (Band2).

\subsection{Land surveying data}

According to the survey data of land use change from 1996 to 2016, the change of ecological land use in recent 20 years was calculated; the evolution trend of ecological land in the past 7 years was carefully analysed according to the 2009 Land Use Status Survey Database and the Land Use Change Survey Database from 2010 to 2016 the study.

\subsection{Basic unit}

Based on the village-level administrative area as the basic unit, the database of land use survey in 2016 is used to study the ecological land use status quo in the Yellow River Delta.

\subsection{Land classification}

Based on research results of the classification of ecological land in China by the researcher Long Hualou [3] and Professor Wang Jing [4], this paper divides and merges the land use types of the Yellow River Delta, including three first-level ecological land use categories and 10 second-level Land use categories, as shown in Table 1.

Table 1. The Ecological Land Classification of Yellow River Delta Area.

\begin{tabular}{|c|c|c|c|}
\hline $\begin{array}{l}\text { Level } 1 \\
\text { class } \\
\text { code } \\
\end{array}$ & $\begin{array}{c}\text { Level } 1 \\
\text { class } \\
\text { name } \\
\end{array}$ & $\begin{array}{l}\text { Level } 2 \\
\text { class } \\
\text { code } \\
\end{array}$ & $\begin{array}{c}\text { Level } 2 \\
\text { class } \\
\text { name } \\
\end{array}$ \\
\hline \multirow{5}{*}{1} & \multirow{5}{*}{$\begin{array}{l}\text { Original ecological } \\
\text { land use }\end{array}$} & 11 & Woodland \\
\hline & & 12 & Grassland \\
\hline & & 13 & Water land \\
\hline & & 14 & Mudflats \\
\hline & & 15 & Saline-alkali land \\
\hline \multirow{4}{*}{2} & \multirow{4}{*}{$\begin{array}{l}\text { Artificial } \\
\text { ecological land use }\end{array}$} & 21 & Arable land \\
\hline & & 22 & Orchard land \\
\hline & & 23 & Artificial woodland \\
\hline & & 24 & Artificial grassland \\
\hline 3 & $\begin{array}{l}\text { Non-ecological } \\
\text { land use }\end{array}$ & 31 & Construction land \\
\hline
\end{tabular}

\section{Method and model}

\subsection{NDVI}

Normalized Difference Vegetation Index(NDVI), unsupervised classification and others were used as remote sensing image data enhance mental methods for the interpretation. NDVI was calculated by formula as:

$$
N D V I i=(N I R i-R i) /(N I R i+R i)[7]
$$

NDVIi is the i-th period Normalized Difference Vegetation Index. NIR $i$ and $R i$ correspond to the near infrared band and the red band of TM and OLI TIRS images, respectively. After the enhancement of the image information, the boundary of human activities on the primary ecology is very clear, mainly including: building roads, building sea dams, reclamation of tidal flats, development of saline-alkali lands, breeding ponds, sun salt fields, reservoirs and residential area. The farthest boundary that these kinds of activities construct for the first time is the boundaries of original ecological land influenced by human activities.

\subsection{Ecological land area index}

Village-level administrative areas were used as the evaluation unit, and the ecological land area index (Ie) were used for the study of the distribution of ecological land in the Yellow River Delta, by the formula as:

$$
I e i=E i / L i
$$

Where Iei is the index of primary ecological land for the i-th unit; $E i$ is the primary ecological land area of the $\mathrm{i}$-th village; $L i$ is the sum of original ecological land, artificial ecological land and non-ecological land in the ith village, which is the total area of the unit.

\section{Findings}

\subsection{The Impact of Human Activities in the Past 30 Years}

The distance between the boundary of original ecological land influenced by human activities and the coastline was calculated by the method according to the research results of Huang Bohua et al. [8]. Figure 1 show that in 1985, the maximum distance from the coastline affected by human activities was $50.41 \mathrm{~km}$, the minimum distance was $6.25 \mathrm{~km}$ and the average distance was $28 \mathrm{~km}$. By 2015 , the maximum distance is $26.23 \mathrm{~km}$, the minimum distance is $0 \mathrm{Km}$, and the average distance is $7.86 \mathrm{Km}$. In the past 30 years, the influence boundary of the original ecological land was push to coastline by an average speed $0.8 \mathrm{~km}$ per year.

Original ecological land such as mudflats, Salinealkali land, Water land, Woodland and Grassland had been gradually replaced by artificial ecological land and Non-ecological land as arable land and construction land. Ecological balance had been destroyed year by year. 


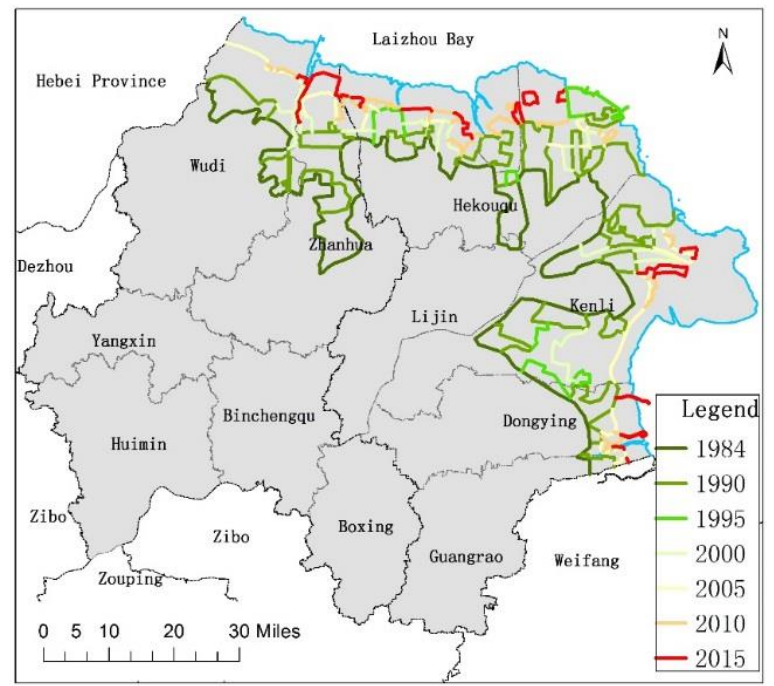

Fig. 1. 1984-2015 Changes in the boundaries of original ecological land in the Yellow River Delta

\subsection{The Changes of Ecological Land in the Past 20 Years}

Land use data from land survey statistics in 1996-2016 clearly shows the change of land use in the Yellow River Delta. It is clear that in the past 20 years, the total area of original ecological land in the study area has decreased by $177250.33 \mathrm{hm}^{2}$, accounting for $30.89 \%$ of the total original ecological land use in 1985, with an average annual decrease of $8862.52 \mathrm{hm}^{2}$, as shown in Chart 1 .

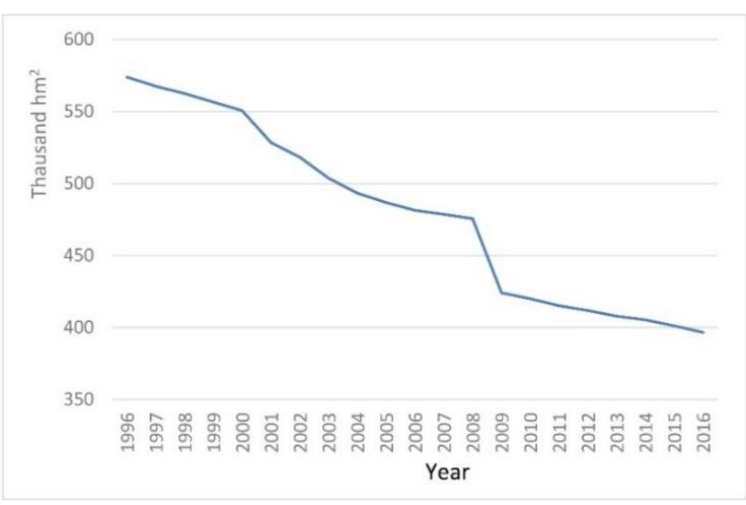

Chart 1. 1996-2016 Changes in the Area of Original Ecological Land in the Yellow River Delta

Among them, the forestland decreased by $3739.93 \mathrm{hm}^{2}$, the mudflats decreased by $36285.33 \mathrm{hm}^{2}$, and the saline-alkali land decreased by $31581.6 \mathrm{hm}^{2}$, as shown in Table 2.

\subsection{The Assessment on Status of Ecological Land and Zoning}

According to the 2016 land use survey data, the primary ecological land area in the Yellow River Delta is $396594.81 \mathrm{hm}^{2}$, the artificial ecological land area is $926810.52 \mathrm{hm}^{2}$, and the non-ecological land area is 293143.23 $\mathrm{hm}^{2}$, the ratio of the three is $24.5: 57.3: 18.1$. In the Yellow River Delta, there are 6,421 village-level units. According to the ecological land area index, with reference to the influence boundary of human activities on the original ecological land in recent thirty years and the change trend of ecological land in the past 20 years, the Yellow River Delta was divided into three zones. They are the general protection of ecological land zone, medium protection zone and key protection zone, as shown in Fig. 2.

Table 2. Comparison Table of Some Ecological Land Areas in the Yellow River Delta between 1996 and 2016

\begin{tabular}{|r|r|r|r|}
\hline \multicolumn{1}{|c|}{ Year } & Woodland & Grassland & $\begin{array}{c}\text { Water } \\
\text { land }\end{array}$ \\
\hline 1996 & 29761.28 & 143178.1 & 29056.1 \\
\hline 2016 & 26021.35 & 27871.88 & 27848.78 \\
\hline $\begin{array}{c}\text { Reduced } \\
\text { area }\left(\mathrm{hm}^{2}\right)\end{array}$ & 3739.93 & 115306.3 & 1207.32 \\
\hline $\begin{array}{c}\text { Reduced } \\
\text { percent(\%) }\end{array}$ & 12.57 & 80.53342 & 4.16 \\
\hline Year & Mudflats & Saline-alkali land \\
\hline 1996 & 150127.4 & 169385.04 \\
\hline 2016 & 113842.1 & \multicolumn{2}{|c|}{137803.44} \\
\hline $\begin{array}{c}\text { Reduced } \\
\left.\text { area (hm }{ }^{2}\right)\end{array}$ & 36285.33 & \multicolumn{2}{|c|}{31581.6} \\
\hline $\begin{array}{c}\text { Reduced } \\
\text { percent(\%) }\end{array}$ & 24.17 & \multicolumn{2}{|c|}{32.79} \\
\hline
\end{tabular}

\subsubsection{General Protection Zone.}

There are 4605 units with the Ie values less than 0.10 , accounting for $71.7 \%$ of the total. Such zones, with less original ecological land, are widely distributed in the Yellow River Delta inland areas. They are mainly distributed in areas far away from the coastline, welldeveloped agriculture and rapid expansion of construction land, such as southwest Guangrao, Boxing, Bincheng, southern Zhanhua, Yangxin, and southern Wudi. The general protection zone should pay attention to the ecological land around the towns and villages, according to the principle of ecological compensation, control construction occupancy, land consolidation and other human activities that may reduce the original ecological land. The region should increase the artificial ecological land such as forestland and garden land to make up for the shortage of original ecological land.

\subsubsection{Medium Protected Zone.}

There are 1718 units with the Ie values between 0.10 0.50 , accounting for $0.26 \%$ of the total. Such zone have relatively more ecological land, and are mainly distributed along the rivers and boundaries of human activities such as Huimin, north-eastern Lijin, south western Kenli, southern estuary, central Zhanhua and central Wudi. The region should strengthen the protection of original ecological land use, with particular emphasis on the protection of original ecological land along the river, control of wastewater discharge, to 
prevent river water pollution. Strict measures should be taken for protection the original ecological land as to control the expansion of residential land, limit agricultural production which lead to the reduce of original ecological land.

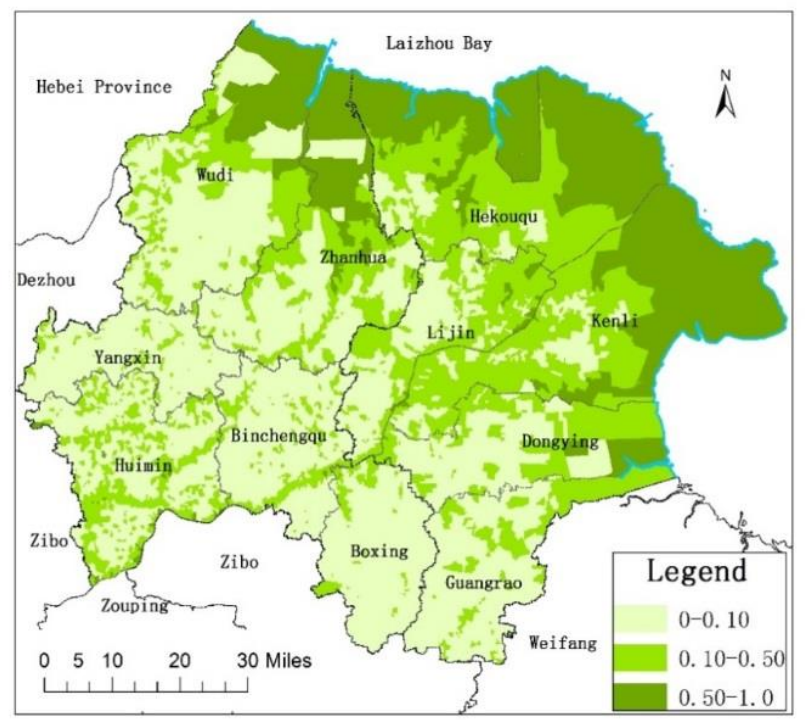

Fig.2. Zoning Map of Ecological Land Use in the Yellow River Delta

\subsubsection{Key Protected Zone.}

There are only 98 units with the Ie values above 0.50 , accounting for $1.5 \%$ of the total. Such zones mainly located in the coastal areas, including the eastern part of Dongying District, Kenli East, northeast estuary, northern Zhanhua, Wudi North. The region is the most affected area for human activities and the most affected by human activities for the last 30 years.

Efforts should be made to increase the protection of ecological land such as river wetlands, mudflats and saline-alkali land, and strictly control the destruction of original ecological land by such activities as pit pond cultivation, beach reclamation, land consolidation and land reclamation from the sea. Under the conditions without affecting the functions and species diversity of ecological land, appropriate improvement or development of saline-alkali land into garden land or woodland in order to increase the green vegetation are permitted.

\section{Conclusion and discussion}

In this paper, based on information as Landsat TM image data, land use statistics and land use status survey database were used on the research of the impact of human activities on the Yellow River Delta, the ecological changes in the Yellow River Delta and Yellow River Delta ecological land use status. The results show that the boundary of original ecological land in the Yellow River Delta had been pushed toward the coastline at an average speed of $0.8 \mathrm{~km}$ per year due to human activities. In the past 20 years, the area of original ecological land decreased by $8862.52 \mathrm{hm}^{2}$ hectares, and a large amount of original ecological land gradually transformed into artificial ecological land. The current proportions of original ecological land, artificial ecological land and non-ecological land in the Yellow River Delta are 25:57:18.

In view of the evolution and status of ecological land in the Yellow River Delta, related local departments should adopt differentiated and focused protection measures to protect the ecological land of the Yellow River Delta. For General Protected Areas, artificial ecological land such as garden land and forestland should be appropriately increased, and the protection of the ecological land around the towns and villages around the village should be emphasized. For Medium-sized Protected Areas, land use as construction land shall be strictly controlled, pollutant discharge should be firmly forbidden, and the protection should focus on original ecological land along rivers; Key Protected Areas should strictly control the pit pond farming, beach reclamation, land reclamation and other activities on original ecological land. Protection of river wetlands, beaches, saline land and other ecological sites should be improved. Appropriate improvement or development of salinealkali lands for the garden or woodland is worthy of consideration. Conclusions as below:

(1) The results show that the Yellow River delta area is strongly affected by human activities. The area of original ecological land decreases rapidly. Nowadays, $71.7 \%$ of the total area of original ecological land in village-level units accounts for less than $5 \%$ in their total area. The distribution of ecological land use is also unbalanced. Overall, there are many coastal distributions and the more inland distributions are less. Differentiated and focused protection measures should be taken to protect the ecological land in the Yellow River Delta.

(2) Using RS-GIS technology and original ecological land area index can reflect the trend and distribution of ecological land in the Yellow River Delta scientifically and accurately, which can provide scientific reference for the formulation of ecological land use protection and land use management policy.

(3) This paper observes and evaluates the ecological land of the Yellow River Delta from the macroscopic level. The change of land use types such as beach, wetland and saline-alkali land in ecological land can be regarded as the key issue in the future.

\section{References}

1. F. Yu, X.B. Li, L.J. Zhang, W.H. Xu, R. Fu, H. Wang. Acta Ecologica Sinica, 35(14), 4931 (2015).

2. H.B. Deng, C.D. Chen, X. Liu, G. Wu, Acta Ecologica Sinica, 29(3): 1519 (2009).

3. H.L. Long, Y.Q. Liu, T.T. Li, J. Wang, A.X. Liu, Chinese Journal of Eco-Environment, 1, 1 (2015).

4. J. Wang, W. Wang, Y. Qi, Y. Qi, T. He, R.J. Wu, Y.Y. Chen, Geogr. Res. 36 (3), 453 (2017).

5. A.B. Wu, Y.X. Zhao, Tran. Chinese Soc. Agr. Eng., 33 (2),283-290 (2017).

6. A. Tang, X. S. Li, Z. F. Bian, Q.W. Yan, Eco. Eco., 32 (5), 136 (2016). 
7. N.P. Robinson, B.W. Allred, M.O. Jones, A. Moreno, J. S. Kimball, D. E. Naugle, T.A. Erickson, A. D. Richardson, Rem. Sen., 9,863 (2017).

8. B.H. Huang, F. Wu, J.K. Xu, Geo. And Inf. Sci. of Wu. Uni., 42 (3),395 (2017). 